\title{
Introduction: a literary studies/games studies conversation
}

Margaret-Anne Hutton and Matthew Barr

\begin{tabular}{|c|c|}
\hline Date of deposit & 20122019 \\
\hline Document version & Author's accepted manuscript \\
\hline Access rights & $\begin{array}{l}\text { Copyright (C) The Author(s), (c) SAGE Publications, } 2019 \text {. This } \\
\text { work is made available online in accordance with the publisher's } \\
\text { policies. This is the author created, accepted version manuscript } \\
\text { following peer review and may differ slightly from the final } \\
\text { published version. }\end{array}$ \\
\hline $\begin{array}{l}\text { Citation for } \\
\text { published version }\end{array}$ & $\begin{array}{l}\text { Hutton, M-A., \& Barr, M. (2019). Introduction: a literary } \\
\text { studies/games studies conversation. Games and Culture, Online } \\
\text { First }\end{array}$ \\
\hline $\begin{array}{l}\text { Link to published } \\
\text { version }\end{array}$ & https://doi.org/10.1177/1555412019884461 \\
\hline
\end{tabular}

Full metadata for this item is available in St Andrews Research

Repository at: https://research-repository.st-andrews.ac.uk/

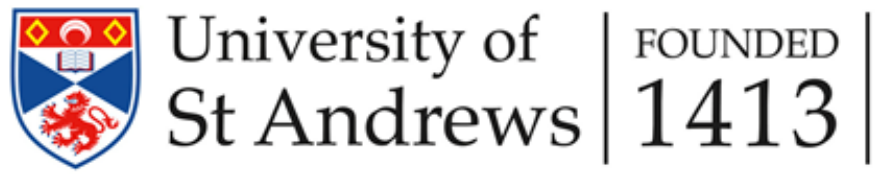




\section{Introduction}

\section{A Literary Studies / Games Studies Conversation}

The articles in this special edition started life as papers delivered at the 'Video Games and Literature: Beyond Stereotypes' event co-organised by colleagues from St Andrews, Glasgow and Abertay Universities. This was the sixth of seven interdisciplinary events run by the Leverhulme International Network for Contemporary Studies, whose aim it was to chart the varying conceptualisations and uses of the terms 'contemporary' and 'the contemporary' in a range of disciplines, sites and practices. ${ }^{1}$ Instead of gesturing towards a summary and synthesis of the published articles, we invite readers to consider them in light of the issues raised in this Introduction, itself a very condensed version of many exchanges between the co-editors. Given the aims of the umbrella Leverhulme project, our first discussion was, unsurprisingly, about the contemporary: if you were teaching a module called 'Contemporary Game[s] [Studies] '2 what would it look like? For a 'Contemporary French Fiction' module students might first be invited to consider possible criteria for text selection. They may opt for a (necessarily arbitrary) cut-off date -- say texts published after 2010--- but is a historical novel set during WWI and published in 2014 'contemporary'? What about a fantasy novel which takes place in an alternative spatio-temporal world? Criteria may be based on innovation (always 'contemporary'?) in form, platform or genre (a novel comprising blogs, or documentary fiction, or fan fiction). Then there are texts about certain 'issues' deemed to be 'contemporary' (a flawed but common approach): migrants, or climate change, or Alzheimer's disease. None of these is ideal, and there are other possibilities.

In a Game Studies context, this problem may also be posed as a discussion point: can we have 'contemporary' games when the origins of the medium remain in living memory? It might be suggested that the evolution of Game Studies feels compressed when compared to, say, Film Studies. The medium's pace of change is faster than film (and probably literature before it), at least from a technological point of view. And, because we're not starting from scratch - instead, building on existing disciplines including Film and Literature, but also Psychology, etc. - Game Studies has experienced growing pains at an accelerated rate. So, one could argue, if we were to suggest a temporal cut-off, it would make sense to refer to 'contemporary games' as those which can be played on the current generation of games consoles. This does, however, exclude PC and mobile gaming, where the broadly accepted generations of consoles are meaningless. It also ignores the fact that many people continue to play games on previous generations' hardware.

Consideration of video games and the 'contemporary' naturally segues into reflections on the history of video games: is writing 'video game history' akin to writing 'literary history', or would these processes involve totally different methodologies and theoretical underpinnings? Does it matter if students studying game development are well-versed in video game history, or, as is increasingly the case in some literature departments; does the modular system contribute to fragmented, dehistoricised learning? There is considerable scope for further

\footnotetext{
${ }^{1}$ For information about all events see https://arts.st-andrews.ac.uk/lincs/. The 'Videogames and Literature' event can be found under the St Andrews 2 tab. Many thanks to the Leverhulme Trust for their generous funding of the Network.

${ }^{2}$ The online blurb for the current V \& A Dundee exhibition 'Videogames: Design / Play / Disrupt', refers to 'the design process behind a selection of ground breaking contemporary videogames', inviting you to 'Immerse yourself in the ground breaking design and culture of contemporary videogames' (our emphasis). https://www.vam.ac.uk/exhibitions/videogames and https://www.vam.ac.uk/dundee/exhibitions/videogames
} 
comparison of pedagogic issues in the fields of literary and game studies, ranging from modes of assessment (asking students to explain why a novel / play / poem would or would not make a good video game might work for both disciplines), to how teaching relates to research, to the relationship between language and literature teaching in Modern Language departments. How, if at all, does this all map onto pedagogic practices in the fields of game studies and games development.

An examination of games and literature might also compare the role and status of agents involved in both fields: game designers, writers, developers and composers; for literary texts, editors and agents; in both cases reviewers and publishers. As a (usually) collaborative enterprise, video games raise potentially interesting questions about the nature of authorship and ownership in relation to literary text production. There is also the relationship between theory(ies) and practice(s), which may appear very different in the respective fields. To what extent are these apparent differences a result of the formal nature of video games, and/or the vocational element involved in the teaching of games? Are some of the gaps and misunderstandings between literature and video game scholars related to the (perceived) difference in the values and aims of social sciences and humanities disciplines? In his defence of the university, Stefan Collini differentiates between 'education' and 'training': "education relativizes and constantly calls into question the information which training simply transmits". ${ }^{3}$ The rise of creative writing programmes within literary studies may also be relevant here. Though this originated in English Departments, modules on creative writing in the target language are now also to be found in Modern Languages departments, and assessment modes are more generally being diversified to include more creative practices. Does the act of creative writing (necessarily) provide insight into 'literature'? What are the limits of learning through doing? The focus on creativity in literature departments extends beyond teaching, with a call for more links between academic research and creative practices. $^{4}$

The idea that Game Studies is the literary scholar's equivalent of literary theory is probably not sound: indeed, what is 'literary theory' now? Are we not 'after theory'? Literary scholars are (just as) likely to look to theories originating in other disciplines - geography, sociology, psychology, computing science and many more. Those involved in teaching 'literature' do not regard literary theory as 'theirs': it is a means to reflect on texts and on the discipline. In terms of undergraduate teaching, analysis of the primary texts and their contexts may take priority over 'literary theory', though these activities cannot readily be separated. And what of 'literature'? So-called 'literary scholars' may both teach and research not only novels, plays and poetry but also film, graphic novels, music, monuments, and yes, video games. It may be worth recalling that Frans Mäyrä (the inaugural chair of DiGRA) defined Game Studies as "...a multidisciplinary field of study and learning with games and related phenomena as its subject matter." One could swap the word 'games' for 'literature' in this definition and it would serve as an accurate description of what literary scholars do. Any interdisciplinary work runs the risk of getting terms muddled up - the nefarious 'narratology' might be relevant here - but surely the aim should be for us work together to move our disciplines forwards? Interdisciplinarity should discover modes of knowledge which individual disciplines miss, as well as aiming to promote disciplinary critical reflexivity.

\footnotetext{
${ }^{3}$ Stefan Collini, What are Universities For? (London: Penguin Books, 2012), p. 56.

${ }^{4}$ The Leverhulme International Network for Contemporary Studies events all involved practioners as well as 'academics'. See also the 2019 'Press Play' conference which 'fuses academic research, creative practice, and civic engagement in a combined conference and exhibition'. http://www.bsr.ac.uk/site2014/wpcontent/uploads/2019/03/Press-Play-Brochure-March-2019-DU37584.pdf
} 
Several of the papers included in this special edition touch upon the notion of canon, whether literary or ludic. Certainly, the idea of a video game canon was keenly debated at the original conference. In establishing a canon, however, issues of quality and taste must first be considered: to a literary scholar, the aesthetic merits of a game may not be immediately obvious. Games' cultural capital and the credibility of those who establish the parameters of taste $^{5}$ may also appear opaque to scholars from other disciplines. The canonical remains a contentious concept in the literary field, where questions of quality, including the extent to which notions of 'literary fiction' (aka 'high') and 'genre fiction' (or 'popular'), still operate. What, then, might the game equivalents be? The idea of a video game canon is not new, and there are, of course, titles that seem to dominate such discussion. It's hard to imagine a video game canon that did not include BioShock, for example, given the sheer volume of academic papers, think pieces and essays it has inspired. But what is the relationship between the video game canon (if such exists) and the present? Is there greater pressure to innovate (partly because of technological advances), for instance? In terms of influence and adaptations, are there more games based on genre literature or on 'canonical' texts, i.e. the 'classics', the 'great works'? Could a great novel come from a game? It is clear that genre literature has exerted a disproportionate degree of influence on video games: one does not have to look very hard to see how the works of Bradbury, Tolkien, Verne and Lovecraft have helped shape the medium, going right back to Spacewar! in 1961. And, theories and methodologies of adaptation and intermediality regularly include video games - see, amongst many others: Bruhn et al.'s Adaptation Studies ${ }^{6}$, Linda Hutcheon's A Theory of Adaptation ${ }^{7}$, the Oxford Handbook of Adaptation Studies ${ }^{8}$ and the Handbook of Intermediality ${ }^{9}$.

There is little doubt that some literary scholars are ill-informed about what Game Studies scholars or game developers are doing, and that equally reductive views of Literary Studies persist. Given the relative paucity of academics trained in both literary and game studies (not to mention game development), more collaborative projects are the obvious way forwards. The conference on which this edition is based is one such collaboration, the success of which has demonstrated the appetite for interdisciplinary work in this field. The conference has also generated valuable discussion about how the disciplines might come together, while also identifying the questions - several of which are posed above - that might be addressed as we continue to bridge the study of literature and games. Discussions between academics and practitioners, sparked by some of the papers published here, also revealed that the lack of an infrastructure that provides opportunities for exchange is a key concern for future collaborative endeavours. Consultation with conference attendees suggested that we might start to remedy this with an online register of Game Studies scholars, Literary Studies scholars and game developers interested in collaboration, alongside the development of an online parallel glossary of terms and concepts drawn from the two fields of study, for example. As in any co-op game, collaboration between players with different yet complementary skills is essential to success. In a squad comprising Game Studies scholars, Literary Studies scholars and game developers, which of us will take on the roles of tank, healer or DPS?

\footnotetext{
${ }^{5}$ Here referring to Bourdieu's Distinction (1979/1984).

${ }^{6}$ Bruhn, Jorgen, Gjelsvik, Anne \& Eirik Hanssen, Adaptation Studies: New Challenges, New Directions (London and New York: Bloomsbury, 2013)

${ }^{7}$ Hutcheon, Linda, A Theory of Adaptation (London and New York: Routledge, 2006)

${ }^{8}$ Leitch, Thomas (ed), Oxford Handbook of Adaptation Studies (Oxford: OUP, 2017)

${ }^{9}$ Rippl, Gabriele (ed.), Handbook of Intermediality (Berlin: De Gruyter, 2015)
} 


\section{Bibliography}

Bruhn, Jorgen, Gjelsvik, Anne \& Eirik Hanssen, Adaptation Studies: New Challenges, New Directions (London and New York: Bloomsbury, 2013)

Collini, Stefan, What are Universities For? (London: Penguin Books, 2012)

Hutcheon, Linda, A Theory of Adaptation (London and New York: Routledge, 2006)

Leverhulme International Network for Contemporary Studies, https://arts.standrews.ac.uk/lincs/

Leitch, Thomas (ed), Oxford Handbook of Adaptation Studies (Oxford: OUP, 2017)

Rippl, Gabriele (ed.), Handbook of Intermediality (Berlin: De Gruyter, 2015) 